This is the final peer-reviewed accepted manuscript of:

Biondi, Beatrice; Camanzi, Luca "Nutrition, hedonic or environmental? The effect of front-of-pack messages on consumers' perception and purchase intention of a novel food product with multiple attributes"

which has been published in final form in FOOD RESEARCH INTERNATIONAL 2020, vol. 130, article n. 108962

The final published version is available online at:

https://doi.org/10.1016/j.foodres.2019.108962

(C) 2019 This manuscript version is made available under the Creative Commons AttributionNonCommercial-NoDerivs (CC BY-NC-ND) 4.0 International License (http://creativecommons.org/licenses/by-nc-nd/4.0/) 


\title{
Nutrition, hedonic or environmental? The effect of front-of-pack messages on consumers' perception and purchase intention of a novel food product with multiple attributes
}

\author{
Beatrice Biondi ${ }^{\mathrm{a}}$, Luca Camanzi ${ }^{\mathrm{a}, *}$ \\ a Alma Mater Studiorum - Università di Bologna, Department of Agricultural and Food Sciences, Viale G. Fanin 50, 40127 Bologna, Italy
}

\section{A R T ICLE INFO}

\section{Keywords}

Consumer perception

Consumer segment

FOP message

Novelty seeking

Willingness to buy

Willingness to pay

\begin{abstract}
A B S T R A C T
The present study aims to assess the effect of different Front-Of-Pack messages on consumer perception, willingness to buy and willingness to pay for a new food product, with multiple attributes, such as particular nutritional information, sensory characteristics, and a potentially positive environmental impact. Furthermore, this study explores the differences between consumers based on their individual latent traits in order to evaluate how these factors affect the willingness to buy the new product, as well as to outline a profile of target consumers attracted by innovative food products. A consumer survey was conducted on a representative sample of 1250 Italian consumers, using a between-subject design with different Front-Of-Pack messages as stimuli. Messages were related to different attributes: nutrition, environmental impact, hedonic characteristics, and process innovation. Empirical findings show that Front-Of-Pack messages do not directly affect consumer willingness to buy, but they do influence consumer perception of the product. The most effective message is the nutrition one. Consumer willingness to buy is particularly influenced by product perception and by their novelty seeking orientation in consumption. Furthermore, consumers were segmented through hierarchical clustering based on their novelty seeking orientation. The results obtained provide valuable suggestions for the design of new products' labeling and for the outline of the profile of potential target customers for innovative food products.
\end{abstract}

\section{Introduction}

Given the overwhelming availability of products in today's Western food market (Chernev, Böckenholt, \& Goodman, 2015), the successful market uptake of new food products relies crucially on both effective consumer targeting and marketing communication. Packaging design and Front-Of-Pack (FOP) label messages are valuable instruments used to attract and to communicate with consumers (McDaniel \& Baker, 1977; Stanton \& Cook, 2019).

Indeed, on-pack communication has the potential to promote healthier food choices (Tórtora, Machín, \& Ares, 2019; Roberto \& Khandpur, 2014) and support the pursuit of a competitive advantage of food companies (Ballco, De-Magistris, \& Caputo, 2019; Nancarrow, Tiu Wright, \& Brace, 1998).

In fact, it has been estimated that $73 \%$ of grocery item purchasing decisions are made at the point of sale, being driven by visual and verbal elements found on the product (Silayoi \& Speece, 2004; Rettie and Brewer, 2000). Visual elements include graphics, colours, size, form and material of the packaging and product. Verbal on-pack com- munication for food products usually conveys information such as the name and/or brand of the product, best-by-date, list of ingredients, nutritional information, preparation instructions, and country of origin. Other verbal information can be written on the label, such as messages or claims.

Various studies revealed that verbal elements of the package are the most important for a consumer's purchase decision (Küster, Vila, \& Sarabia, 2019; Kuvykaite, Dovaliene, \& Navickiene, 2009; Silayoi \& Speece, 2004). In fact, food product labels display a variety of messages that refer to both search and credence attributes which can lead consumers to pay a premium for such products (Bernard, Duke, \& Albrecht, 2019; Mueller Loose \& Szolnoki, 2012). Nevertheless, information displayed on the label should be brief to avoid creating a so-called 'information overload' in the consumer (Chernev et al., 2015; Wansink, Sonka, \& Hasler, 2004). This is why, in order to be effective, both verbal and visual elements of the packaging must be short and simple. While nutrition claims refer to nutritional properties of the product that highlight its benefits due to the nutrients it contains or does not contain, health claims are statements about a relationship

Abbreviations: CNS, consumer novelty seeking; FCQ, food choice questionnaire; FOP, front-of-pack; WTB, willingness to buy; WTP, willingness to pay. * Corresponding author.

E-mail address: luca.camanzi@unibo.it (L. Camanzi) 
between food and health that is supported by scientific evidence. In general, the use of claims on food products is regulated by governmental authorities. In the EU, nutritional and health claims are regulated by the EC Regulation n. 1924/2006. In the United States, the USDA provides labelling guidance, which ensures that all labels are truthful and not misleading (USDA, 2014). Examples in Europe are the FOP nutrition label formats currently in use, i.e. Multiple Traffic Lights, Guideline Daily Amounts, Green Tick and the 5-Colour Nutrition Label (Ducrot et al., 2016). Examples in the US are the Facts Up Front label, the Smart Choices icon and the Traffic-Light-Guideline Daily Amounts (Gorski Findling et al., 2018; Roberto, Bragg, et al., 2012, Roberto, Shivaram, et al. 2012; Andrews, Burton, \& Kees, 2011). Other FOP nutrition content claims include general statements, such as "source of calcium", "source of vitamin $\mathrm{B}_{6}$ ", "> 100\% RDA of vitamin C", "high fiber" "low calories", "fat free", and "sugar free" (Ballco et al., 2019; Menger-Ogle \& Graham, 2018; (Huang and Lu, 2016)). Newman, Burton, Andrews, Netemeyer, and Kees (2018), Kaur, Scarborough, and Rayner (2017) and Hawley et al. (2013) provided comprehensive literature reviews on this topic. Besides health and nutrition attributes, FOP elements may also convey information concerning production and/or packaging technology and related sustainability. Sustainability labels are regarded as key tools in informing consumers of the environmental, social and ethical impacts of their food choices (Van Loo et al., 2015; Krystallis, Grunert, de Barcellos, Perrea, \& Verbeke, 2012). Examples of sustainability labels are certification labels, such as "Organic", "Fair Trade", and "Rain Forest Alliance", (Annunziata, Mariani, \& Vecchio, 2019). In the absence of a certification, in most countries of the world (including the EU and the US), self-declared claims, such as "environmentally friendly", "green" or "ecological," should not be used because they are vague and non-specific (European Commission, 2016; Federal Trade Commission, 2012; International Organization for Standardization, 2008). However, research has showed that such claims may have a significant impact on consumer WTP (Cecchini, Torquati, \& Chiorri, 2018; Cagalj, Haas, \& Morawetz, 2016).

A further issue for a successful marketing strategy for new food products is targeting appropriate consumer segments by developing the whole marketing strategy towards specific needs and preferences of the target group. Various authors contributed to the identification of groups of consumers with similar preferences in the food domain. Earlier studies mostly only considered demographic variables for segmentation (e.g. income, age, education, family size and composition, etc.) (Panzone, Hilton, Sale, \& Cohen, 2016; Van Der Zanden, Van Kleef, De Wijk, \& Van Trijp, 2014; Albisu et al., 2011). However, recent segmentation research has focused more on psychological and lifestyle variables, which are assumed to be traits responsible for heterogeneous behaviours (Grunert, 2019; Biondi et al., 2019; Verain et al., 2012). According to Vanhonacker et al. (2013), the traditional food sector would benefit from enhanced product customization and communication towards specific consumer segments.

All of these issues are particularly challenging when innovative food products are concerned. In fact, in this case, consumer preferences are driven more by extrinsic cues rather than by intrinsic product qualities (Küster et al., 2019; Vila-López \& Küster-Boluda, 2018). Moreover, when choosing an innovative food product, consumers pay greater attention to the benefits it conveys rather than to its physical characteristics (Caracciolo et al., 2019; Küster et al., 2019). Galati, Tulone, Moavero, and Crescimanno (2019) also argue that there is a real potential for the diffusion of new technology in the food industry but also the need to define the consumers' profile.

In light of the above, the present study aims to assess the effect of different FOP messages on consumer perception, willingness to buy (WTB), and willingness to pay (WTP) for a novel food product, carrying multiple attributes. This novel food product is a new condiment with particular nutritional and sensory characteristics that was obtained through an innovative production process with a potential positive environmental impact.

Furthermore, the study explores the differences between consumers, based on individual latent traits (i.e. food choice determinants and novelty seeking) and socio-demographics, in order to evaluate how these factors affect the willingness to buy the new product and to outline a profile of target consumers attracted by innovative food products, namely condiments.

\section{Theoretical background and research hypotheses}

The appearance of the product packaging represents the first contact between the consumers and the food product (Shepherd, Sparks, Bellier, \& Raats, 1991). In addition, consumers make inference and form expectations about the product based on information conveyed by the product pack through the messages and claims (Carrillo, Varela, \& Fiszman, 2012). Various contributions in the scientific literature assessed how these elements might act as an incentive to buy (Rettie and Brewer, 2000). In the following sections we recall three lines of research considered most relevant for the purpose of the present study and we formulate a set of research hypotheses accordingly.

\subsection{FOP claims effect on consumer product perception and WTB}

In regard to the effect of nutrition and health claims, research provided heterogeneous results. On the one hand, a large number of studies showed that there is often a positive relationship between FOP nutrition and health claims and consumer perception of product healthiness and purchase intention. Priven, Baum, Vieira, Fung, and Herbold (2015) demonstrated that free-from labelled products increase the perception of healthiness. Carrillo et al. (2012) studied the interaction between sensory and non-sensory characteristics that influence the overall acceptance and perceived healthiness of enriched biscuits and/or biscuits with reduced levels of high energy components under three different scenarios (blind, informed and expected conditions). They found that non-sensory cues like FOP claims affect healthiness perception and WTB.

On the other hand, recent studies suggest that FOP messages influence only consumers' perception and not their purchasing patterns. For instance, Gorski Findling et al. (2018) showed that although front-of-package labels helped participants more accurately assess products' nutrition information, there were no conditions that shifted purchase intentions. Similarly, Roberto, Bragg, et al. (2012), Roberto, Shivaram, et al. (2012) found that FOP labels influence consumers' perceived healthiness of the product, with having little impact on consumer WTP. Finally, Menger-Ogle and Graham (2018) also found a weak effect of nutrition FOP claims on consumer perception of healthiness and WTB in the case of snack foods.

Besides nutrition and health claims, research has been conducted regarding the effect of other types of FOP messages (e.g. hedonic and environmental messages) on product perception and consumption patterns. For instance, Oliveira, Ares, \& Deliza, 2018, showed that the influence of hedonic claims ("premium product", "same flavour, less sugar") on consumers' perception was modulated by their hedonic sensitivity towards sugar-reduction in the case of orange/passionfruit nectars. Gracia, Barreiro-Hurlé, and Galán (2014) studied consumer perception for production method-related claims, showing that consumers are willing to pay a positive premium price for an enhanced method of production, as well as for the proximity of production (local, regional and national over imported). In addition, effects of environmentally-friendly labels and sustainability claims have been assessed in the literature. Results indicate that consumers value environmentally-friendly attributes (such as "organic", "carbon trust") displayed on labels (De Marchi, Caputo, Nayga, \& Banterle, 2016) and that the 
perceived naturalness of the product induced by package and product sustainability messages explains the perception of product quality (Magnier, Schoormans, \& Mugge, 2016).

However, to the best of our knowledge, few studies have considered simultaneously the effect of different types of FOP claims. One example is the paper by Cagalj et al. (2016) on organic products who found that the claims related to the environmental and health dimensions equally increased the WTP for the product, whereas the "taste" claim had no effect on the WTP. Moreover, Darian and Tucci (2011) found that effective promotions for food products should include taste and high nutritional value attributes.

Based on these considerations, we formulate the first two research hypotheses:

\section{H1: FOP claims influence consumer perception of the product}

We predict that claims highlighting different attributes of the product (i.e. concerning nutrition properties/hedonic value/environmental-friendly production/process innovation) will enhance consumer perception of different dimensions related to the choice of food. Specifically, we expect that consumers exposed to the claim highlighting the nutritional value of the food product (i.e. the "nutrition" claim) will perceive it as healthier and more natural, with respect to consumers in the control group and to those exposed to other claims. Similarly, we expect that consumer viewing the "hedonic" claim will perceive the product tastier and easier to use; that consumers exposed to the "environmental" claim will have an increased perception of the environmental performance of the product and that consumers viewing the "process" claim will perceive it as more innovative, as compared to consumers in the control group and to those exposed to other claims (see Section 3.4 for the list of claims considered). Furthermore, the study explores the relationships between each of the claims and consumer perception of the product as both familiar (since it may be associated with traditional olive oil) and expensive.

H2: Consumer perception of the product influences consumer WTB

We also predict that enhanced perception of such attributes will increase consumer WTB the product. The hypothesized relation between consumer perceptions and willingness to buy is supported by empirical evidence. Recently, Huang and Lu (2016) found that the perception of food healthiness significantly influenced consumer purchase intention of packaged foods. Further empirical research has shown that the healthiness perception affects consumer purchase intention for food products (Ares \& Gámbaro, 2007; Ragaert, Verbeke, Devlieghere, \& Debevere, 2004).

\subsection{Product specificity}

As highlighted above, previous studies on the effects of claims had different results, based on the specific food category and product considered. Among these, van Kleef, van Trijp, and Luning (2005) and Verbeke, Scholderer, and Lähteenmäki (2009) tested the effect of FOP claims for functional foods, obtaining significant but different results depending on the type of claim and on the carrier products. Later, Hellier et al. (2012) studied the effects of label colour, wording, content and information source on perceived hazard and WTB for GM food, finding significant differences among treatments. Recently, Vila-López and Küster-Boluda (2018) manipulated colour and health claims and confirmed that both kinds of attributes have a significant impact on young consumer attitudes and product trial.

According to Koutsimatis et al. (2012) and Murray and Delahunty (2000), attributes related to the type of packaging material and its colour have the potential to make the product more or less appealing and influence consumer willingness to buy. Furthermore, Varela, Ares, Giménez, and Gámbaro (2010) studied the influence of packaging on consumers' liking of orange-flavoured powdered drinks, finding a significant impact on consumers' liking scores.
In light of the above, we formulate a third research hypothesis that takes into account the effects of product and packaging characteristics on consumer WTB:

H3: Liking of product and packaging features influence consumer WTB

This hypothesis allows for the consideration of individual liking of extrinsic features of the product as one of the drivers of consumer choice. Specifically, we intend to evaluate consumers' liking of extrinsic cues for the considered product and we expect that the liking of one or more product features, i.e. shape, material and size of the bottle, colour of the label, colour of the condiment - will positively affect consumer WTB (the higher the liking, the higher the WTB).

\subsection{Consumer individual characteristics and psychological processes}

Another line of research that is of interest for the present study assesses individual characteristics and psychological processes involved in consumer evaluation of packaged food products based on extrinsic cues. As already mentioned, visual elements of food products can play an important role in determining food choice through shaping the attributes' perception of consumers (Cavallo \& Piqueras-Fiszman, 2017; Carrillo et al., 2012). The extrinsic cues on the package are intended to catch the attention of consumers and to convey information relevant for their evaluation of the product. However, the variety of attributes and the limited time available to make choices induce consumers to make inference and form expectations about the product based on a sub-set of information in different ways, leading to disparate outcomes (Ballco et al., 2019). Heterogeneity in accounting for the effects of FOP claims has been explored and attributed to various factors. Some of the drivers which have been found to influence consumers' perceptions or food selection include socio-demographics, such as gender, age, socioeconomic status, education (D'Souza, Taghian, Lamb, \& Peretiatko, 2007; Nayga, 1997), cross-cultural differences (Van Wezemael, Caputo, Nayga, Chryssochoidis, \& Verbeke, 2014), and individual psychological processes. Among these, various authors pointed out the importance of psychological variables, including knowledge, cognitive restraint, and general health interest (Benson et al., 2018; Cavaliere, Ricci, \& Banterle, 2015). Further research revealed that consumer response to FOP claims may also depend on the specific claim, product category and familiarity with it (Bialkova, Sasse, \& Fenko, 2016; van Trijp \& van der Lans, 2007).

In light of the above, we formulate the fourth research hypothesis:

\section{H4: Individual latent traits influence consumer WTB}

More precisely, we consider individual latent traits related to food choice and the search for novelty in consumption. We specifically consider individual differences in motives underlying the selection of food and the difference in degree of individuals' tendency to search for novelty when shopping for food based on the hypothesis that these latent traits affect WTB for the considered product (see Section 3.4 and Table A. 1 and Table A. 2 for further details concerning the latent traits investigated).

Specifically, we expect that the more consumers seek for novelty when shopping, the more they are willing to buy a product that represents a novelty for the market. Furthermore, we predict that the more consumers consider important the healthy and natural content and the sensory appeal in the choice of food, the higher will be their WTB for a product with such attributes. Finally, we expect that consumers that consider price important in the choice of food (i.e. they look for less expensive or good value for money products) will have a lower WTB.

In summary, we predict that packaging design, specifically the features and claims, influence perception and liking, respectively. These then determine WTB together with latent traits of the individual. 


\section{Material and methods}

\subsection{Object of the study}

The product considered in the experiment is a novel vegetable oil called Tolly ${ }^{\circledR}$ that has multiple attributes.

Firstly, Tolly ${ }^{\circledR}$ is obtained through the co-milling of olives with industrial tomato by-products (i.e. tomato skins and seeds), following the circular economy principle according to which "the value of products and materials is maintained for as long as possible; waste and resource use are minimised, and resources are kept within the economy when a product has reached the end of its life, to be used again and again to create further value" (European Commission, 2015). To this end, an LCA analysis was conducted according to ISO 14040 standards and considered $100 \mathrm{ml}$ of product in the aluminium package as a functional unit, which is portrayed in Fig. 2. The LCA made it possible to evaluate alternative technological and logistical options in the various life cycle stages considered and to optimize the system that selects the solutions with a positive or at least minimal environmental impact (Scalbi, Bendini, Biondi, Camanzi, Cascone, Chiavetta, Sposato, Tesini, Valli, \& Gallina Toschi, 2019). As for the provisioning, since tomato industry by-products are usually conferred to food manufacturers, the transportation to the milling plants does not entail a greater environmental impact as compared to the current solution for their disposal. In the processing stage, the use of an ultrasound-assisted process allowed for a reduction of the related environmental impacts, thanks essentially to an important increase in extraction yields (about $2 \%$ compared to traditional co-milling), but also to the possibility of controlling the process' temperatures and avoiding using solvents (Almeida, Valli, Bendini, \& Gallina Toschi, 2017). Furthermore, the management solutions proposed for the end-of-life pomace and pits (bio digestion and combustion in the boiler) avoid the generation of the impacts related to methane production.

Secondly, besides preserving the well-known features of a conventional virgin olive oil in terms of sensory and nutritional value, Tolly® is characterized by additional properties linked to the presence of lycopene and $\beta$ - carotene, which act as natural antioxidants with potential benefits for human health (Kaulmann \& Bohn, 2014).

Finally, Tolly® has particular sensory characteristics: it has a bright red-orange colour and a fragrant bouquet of scents, which are reminiscent of both olives and tomatoes.

\subsection{Survey setting}

A Computer Assisted Web Interviewing (CAWI) survey was conducted on a stratified sample of 1250 Italian consumers responsible for food purchases in their household. The CAWI methodology makes it possible to collect responses from a large panel of consumers through specialized service providers. The sample was extracted from a list containing nearly four hundred thousand consumers. Based on the strata identified, the sample can be considered representative of the Italian population by gender, age group and geographical location (North-West, North-East, Center and Southern regions). The questionnaire was implemented on a web-platform by the authors, and consumers in each stratum were randomly sent a web-link pointing to the online questionnaire. Descriptive statistics of the sample are displayed in Table 1.

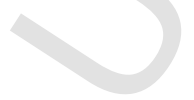

\footnotetext{
1 Tolly ${ }^{\circledR}$ is one of the outcomes of the "Food Crossing District" regional-funded project, carried out by the University of Bologna and is a patent by Alma Mater Studiorum - Università di Bologna. More information available at https://site.unibo.it/ foodcrossingdistrict/it.
}

Table 1

Descriptive statistics of the sample and corresponding shares of the Italian population.

\begin{tabular}{lll}
\hline & Sample $(\mathrm{n}=1250)$ & Italian population $(\mathrm{N}=60.5 \mathrm{mln})$ \\
\hline Female & $50.52 \%$ & $50.25 \%$ \\
NE & $18.84 \%$ & $18.99 \%$ \\
NW & $26.19 \%$ & $26.19 \%$ \\
Center & $20.21 \%$ & $19.85 \%$ \\
South & $34.76 \%$ & $34.97 \%$ \\
18-34 years old & $28.54 \%$ & $28.75 \%$ \\
35-49 years old & $36.14 \%$ & $35.71 \%$ \\
50-65 years old & $35.33 \%$ & $35.54 \%$ \\
\hline
\end{tabular}

\subsection{Experimental design}

The experiment aiming to test for the effect of the claims was implemented using a between-subject design. The overall sample was randomly and equally divided into five sub-groups and each group was presented with a different image of the product, i.e. 'treatment'. Each treatment differed for the FOP message displayed on the label. Four different messages were tested plus a control treatment with no FOP message.

The online questionnaire was composed of three main parts. In the first section, the appearance of the product was presented to the respondents (see Fig. 1, in Italian). The control group saw the picture of the product displaying only the description on the label, i.e. "Condiment obtained from the co-pressing of olives, tomato peel and seeds." The other groups saw the picture of the product with one of the following FOP messages inserted below the product description on the label ${ }^{2}$ :

a) "Naturally rich in antioxidants" ('nutrition' claim);

b) "Full resource exploitation in a circular economy perspective" ("environmental' claim);

c) "Adds a pleasant taste and colour to your dishes" ('hedonic' claim);

d) "Obtained by an innovative physical-mechanical process" ('process' claim).

Then, a picture of the condiment showing its colour was presented to all respondents (Fig. 2) with a short description of its organoleptic characteristics:

"Tolly ${ }^{\circledR}$ has an intense orange colour; it has the typical taste of olive oil and a hint of the scent of tomatoes." Specific questions were then addressed to collect information about their liking and perception of the product: WTB and WTP, respectively. In the second section of the questionnaire, questions about consumption habits regarding olive oil were displayed. Finally, in the third section of the questionnaire, respondents were presented with psychological scales aimed at gathering information on consumer novelty-seeking disposition, food choice motives, and socio-demographic questions.

\subsection{Measures}

Consumer perception of the product was measured through eight semantic differential items related to healthiness, ease-of-use, familiarity, innovativeness, taste, cost, naturalness and environmental friendliness. These items have been selected from the food choice motives proposed by Steptoe, Pollard, and Wardle (1995) based on their rele-

\footnotetext{
2 Translation from the original messages, in Italian. The FOP messages were implemented using an image processing software, altering a photograph of the product prototype. Pictures of the products were shown to participants as color images on the screen.
} 


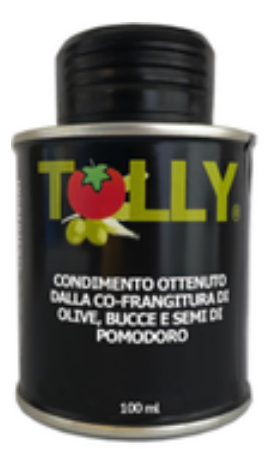

control
(no claim)

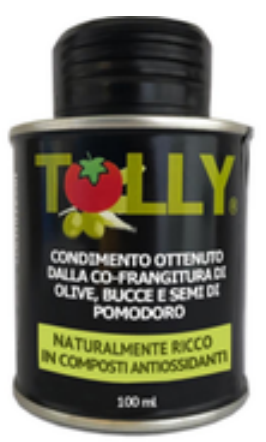

a) nutrition claim

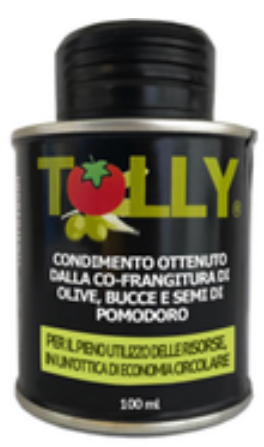

b) environmental

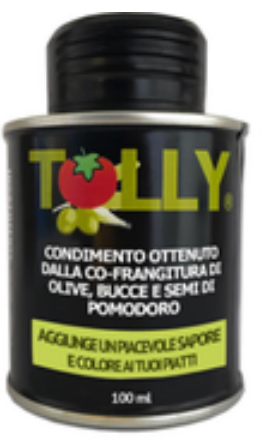

c) hedonic claim

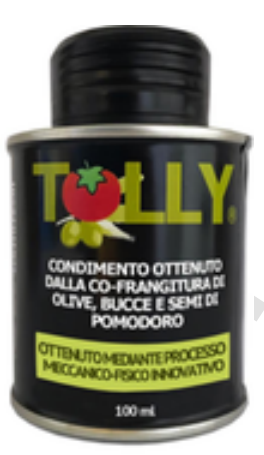

d) process claim

Fig. 1. Visual stimuli displayed to the 5 sub-groups of respondents - packaging and FOP claim.

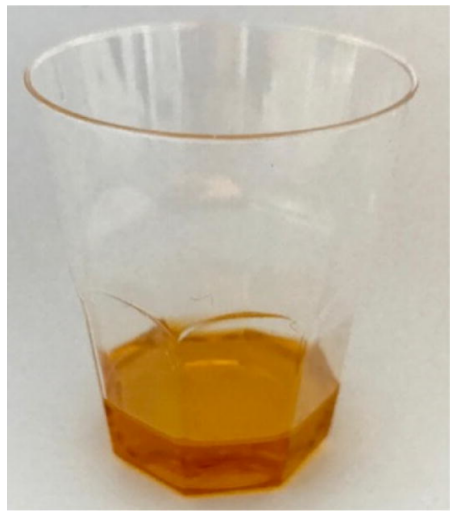

Fig. 2. Visual stimuli displayed to all the respondents - product colour.

vance for the product considered. These items were rated based on a semantic differential scale, from -5 to 5 (where 0 is the neutral response). Liking of packaging characteristics (colour, material, shape, size) and colour of the condiment were assessed based on a star rating system from one to five. The choice of different scales was made considering the different nature of the items included in the questionnaire. In fact, each particular question-format requires adequate response-formatting: semantic differential items are measured including a neutral point (i.e. negative and positive ratings with reference to zero), while liking cannot be negative and is measured on a five-star rating type of question (Bradley \& Lang, 1994). Then, the willingness to buy (WTB) the product was assessed in terms of probability to buy the product in the next shopping for condiments, on a scale from 0 to 100 . Willingness-To-pay (WTP) was measured by means of an open-ended question format: each respondent directly stated his/her hypothetical WTP for the $100 \mathrm{ml}$ bottle. This is one of the methods that are used in the consumer literature to assess WTP, and it has been shown to outperform indirect methods in estimating WTP in case of low-cost, frequently purchased, nondurable products like groceries (Miller, Hofstetter, Krohmer, \& Zhang, 2011).

To classify consumers based on their level of novelty seeking in consumption, the Consumer Novelty Seeking (CNS) scale was included in the questionnaire (Manning, Bearden, \& Madden, 1995). The scale is made up of eight items (see Table A.1 in the Appendix for the complete list of items). Furthermore, food choice motives were assessed using some of the items of the Food Choice Questionnaire (FCQ) by Steptoe et al. (1995). To limit the burden for respondents, we retained only the dimensions related to health ${ }^{3}$, sensory appeal, natural content,

\footnotetext{
${ }^{3}$ Only the first three items retained.
}

and price, since these are the most interesting motives in relation to the product object of the research.

\subsection{Analysis}

Whether the perception of the product, liking of the product's features, WTB or WTP differ between treatment groups was tested through Kruskal-Wallis tests (at a 0.05 significance level). Principal Component Analysis (PCA) was applied to the CNS and FCQ scale items to reduce dimensions. As part of the analysis, these latent traits were evaluated in relation to WTB and WTP, by Pearson bivariate correlation. Linear regression was performed to examine whether WTB depends on perceptions, liking, latent traits, socio-demographics and treatment in the experiment. Lastly, in order to segment consumers by their novelty-seeking attitude, hierarchical clustering was applied, profiling the clusters with socio-demographics, food choice motives, and consumption related variables.

\section{Results}

After the data cleaning operation, 1231 valid responses were retained for analysis. Descriptive statistics show that, in general, the product is perceived as innovative and easy to use (Table 2). Additionally, consumers, on average, perceive the condiment as produced with respect for the environment, having a pleasant taste, being rather healthy and containing natural ingredients. At the same time, consumers consider Tolly® as unfamiliar and have on average a neutral perception regarding its price on the market.

Kruskal-Wallis tests (Table 3) were performed to check for differences in product perception among treatment groups. Statistically significant differences emerge based on the claim consumers saw on the

Table 2

Perception of the product: average value of semantic differential items (from -5 to 5 ).

\begin{tabular}{lll}
\hline & Average & $\begin{array}{l}\text { Standard } \\
\text { error }\end{array}$ \\
\hline Not healthy - Healthy & 1.03 & 0.07 \\
Cheap - Expensive & 0.34 & 0.07 \\
Unfamiliar - Familiar & -1.68 & 0.08 \\
Difficult to use - Easy to use & 1.98 & 0.07 \\
Unpleasant taste - Pleasant taste & 1.23 & 0.07 \\
Contains artificial additives - Contains natural & 1.00 & 0.08 \\
ingredients & & \\
Produced without - with respect for the environment & 1.36 & 0.07 \\
Traditional - Innovative & 2.35 & 0.06 \\
\hline
\end{tabular}


Table 3

Kruskal-Wallis test results

\begin{tabular}{lll}
\hline & $\begin{array}{l}\text { Kruskal-Wallis } \\
\text { chi-squared }\end{array}$ & $\begin{array}{l}\text { P- } \\
\text { value }\end{array}$ \\
\hline Not healthy - Healthy & 9.73 & 0.05 \\
Cheap - Expensive & 10.25 & 0.04 \\
Unknown - Familiar & 5.28 & 0.26 \\
Difficult to use - Easy to use & 11.51 & 0.02 \\
Unpleasant taste - Pleasant taste & 14.69 & 0.01 \\
Contains artificial additives - Contains natural & 10.44 & 0.03 \\
ingredients & & $<0.01$ \\
Produced without respect for the environment - & 17.18 & \\
Produced with respect for the environment & & $<0.01$ \\
Traditional - Innovative & 15.41 &
\end{tabular}

label. The only not significant difference among treatment groups regards the perception of the product being familiar.

Post-hoc tests (Table 4) indicate that respondents exposed to the 'nutrition claim', on average, rated significantly higher in perceived healthiness, taste, naturalness, innovativeness, and environmental friendliness of the product in respect to the control group. Significant differences were also found in perceived environmental friendliness of the product between respondents in the environmental treatment and those in the control and hedonic groups, the former group giving higher scores than the latter. Furthermore, consumers in the hedonic treatment perceived (or: expected) the product as tastier than those in the control treatment. Lastly, being shown the process-related or environmental-friendly claim on the label significantly increases the perception of the product as innovative.

Concerning liking for the features of the packaging and for the colour of the condiment, average liking rates lie between 2.8 and 3.4 , on a scale from one to five. The different claims seen on the label do not produce a significant influence on consumers' liking of product features according to Kruskal-Wallis tests. In regard to WTB, only $5.5 \%$ of the sample indicated zero probability to buy the product, and the overall average rating was 44 (out of 100). The average willingness to pay $^{4}$ for the $100 \mathrm{ml}$ bottle was $€ 2.35$. No statistically significant differences were found in WTB and WTP between treatments. The PCA applied to the CNS scale items resulted in one component explaining around $67 \%$ of total variance (see Table A.1 in the Appendix for loadings, the scree-plot is available as supplemental material). The PCA conducted on the FCQ scale items, with Varimax rotation, resulted in three components, explaining $68 \%$ of the total variance (see Table A.2 in the Appendix for loadings, the scree-plot is available as supplemental material). These new components are called "Healthy and Natural" (HN) content, "Sensory Appeal" (S) and "Price" (P). The correlation between each component and WTB and WTP was computed (Table 5). The consumer novelty-seeking orientation was found to be positively and mildly correlated with the WTB and also with the WTP, although to a smaller degree. This means that the more consumers look for novelty in their shopping, the more they are willing to buy and to pay for the new condiment. Furthermore, choice motives are significantly correlated with WTB and WTP, even if the strength of the correlation is lower than that of the correlation found with consumer novelty-seeking attitude. In particular, the more the general sensory appeal is important for consumers, the more they are willing to buy the product; this effect appears also in respect to the importance of a healthy and natural content in the choice of food. On the contrary, the more price is considered as

\footnotetext{
4 The WTP is calculated only on those indicating a probability of buying the product above zero.
}

Table 4

Post-hoc test result (Dunn test) adjusted for multiple comparisons (Holm method).

\begin{tabular}{|c|c|c|c|}
\hline & & Adj. P-value & $\begin{array}{l}\text { Average } \\
\text { difference }\end{array}$ \\
\hline \multicolumn{4}{|c|}{ Not healthy - Healthy } \\
\hline Control & Nutrition & 0.02 & -0.64 \\
\hline \multicolumn{4}{|c|}{ Unpleasant taste - Pleasant taste } \\
\hline Control & Nutrition & 0.02 & -0.74 \\
\hline Control & Hedonic & 0.03 & -0.61 \\
\hline \multicolumn{4}{|c|}{ Contains artificial additives - Contains natural } \\
\hline \multicolumn{4}{|c|}{ ingredients } \\
\hline Control & Nutrition & 0.03 & -0.73 \\
\hline \multicolumn{4}{|c|}{ Produced without - with respect for the environment } \\
\hline Control & Nutrition & 0.04 & -0.61 \\
\hline Control & Env. friendly & 0.01 & -0.63 \\
\hline Hedonic & Env. friendly & 0.05 & -0.59 \\
\hline \multicolumn{4}{|c|}{ Traditional - Innovative } \\
\hline Control & Nutrition & 0.01 & -0.56 \\
\hline Control & Process & 0.01 & -0.50 \\
\hline Control & Env. friendly & 0.04 & -0.45 \\
\hline
\end{tabular}

Table 5

Correlation between WTB, WTP and latent traits.

\begin{tabular}{|c|c|c|c|c|c|}
\hline & & $\begin{array}{l}\text { Consumer } \\
\text { novelty } \\
\text { seeking }\end{array}$ & $\begin{array}{l}\text { Healthy and } \\
\text { natural } \\
\text { content }\end{array}$ & $\begin{array}{l}\text { Sensory } \\
\text { appeal }\end{array}$ & Price \\
\hline WTB & $\begin{array}{l}\text { Pearson } \\
\text { correlation }\end{array}$ & $0.40^{* * *}$ & $0.09^{* *}$ & $0.15^{* * *}$ & 0.00 \\
\hline WTP & $\begin{array}{l}\text { Pearson } \\
\text { correlation }\end{array}$ & $0.20^{* * * *}$ & 0.04 & 0.01 & $-0.10^{* *}$ \\
\hline
\end{tabular}

* p-value $<0.05 ; * *$ p-value $<0.01 ; * * *$ p-value $<0.001$.

important when choosing food, the less consumers are willing to pay for the product.

A linear regression was then estimated to assess the effect of product extrinsic cues and consumer socio-demographics, choice motives, and personal traits on consumers' WTB. The Adjusted $\mathrm{R}^{2}$ is 0.66 , meaning that the included variables have good explanatory power; estimated coefficients are displayed in Table 6. Surprisingly, neither the socio-demographic variables nor the FOP message written on the label significantly affect the WTB the product. On the other hand, perceptions and liking of the product, together with the consumer novelty-seeking and the importance of price when choosing food, significantly contribute to explaining the variance of WTB.

The coefficient with the highest estimate relates to the liking of the colour of the condiment, followed by CNS, perception of healthiness of the product, and liking of the material of the bottle. However, each coefficient refers to its own scale, i.e. liking is measured on a scale from one to five, whereas perceptions were assessed on a ten-point scale, which makes it difficult to compare the magnitude of coefficients across variables. Still, the CNS variable has a strong statistically significant and a rather high impact on willingness to buy, meaning that novelty-seekers in the consumption domain are more willing to buy the product.

Given this result, we profile consumers that look for novelty when shopping based on a hierarchical clustering performed on the CNS items. From the analysis emerges the conclusion that the optimal number of clusters is two. The first cluster contains consumers that rated significantly higher in CNS items overall in respect to the second cluster. Therefore, it has been called "novelty seekers" (31\% of the sample), while the second cluster is identified as "conventional consumers." 
Table 6

Linear regression on WTB: Estimated coefficients.

\begin{tabular}{|c|c|c|c|}
\hline & $\beta$ & $\begin{array}{l}\text { Standard } \\
\text { Error }\end{array}$ & $\begin{array}{l}\mathrm{p}- \\
\text { value }\end{array}$ \\
\hline Constant & 7.74 & 2.06 & $<0.01$ \\
\hline \multicolumn{4}{|l|}{ Product perception (H2) } \\
\hline Not healthy - Healthy & 2.93 & 0.35 & $<0.01$ \\
\hline Cheap - Expensive & -0.42 & 0.22 & 0.06 \\
\hline Unfamiliar - Familiar & 1.25 & 0.23 & $<0.01$ \\
\hline Difficult to use - Easy to use & 1.22 & 0.28 & $<0.01$ \\
\hline Unpleasant taste - Pleasant taste & 1.08 & 0.33 & $<0.01$ \\
\hline $\begin{array}{l}\text { Contains artificial additives - Contains } \\
\text { natural ingredients }\end{array}$ & 0.64 & 0.29 & 0.03 \\
\hline $\begin{array}{l}\text { Produced without - with respect for the } \\
\text { environment }\end{array}$ & 0.01 & 0.31 & 0.97 \\
\hline Traditional - Innovative & 0.72 & 0.28 & 0.01 \\
\hline \multicolumn{4}{|l|}{ Product liking (H3) } \\
\hline Shape of the bottle & 0.63 & 0.64 & 0.33 \\
\hline Material of the bottle (tin) & 2.13 & 0.57 & $<0.01$ \\
\hline Colour of the label & 1.34 & 0.59 & 0.02 \\
\hline Size of the bottle $(100 \mathrm{ml})$ & -0.40 & 0.55 & 0.47 \\
\hline Colour of the condiment & 6.47 & 0.54 & $<0.01$ \\
\hline \multicolumn{4}{|l|}{ Individual latent traits (H4) } \\
\hline Novelty seeking & 3.15 & 0.62 & $<0.01$ \\
\hline Healthy and natural content & -0.42 & 0.55 & 0.44 \\
\hline Sensory appeal & 0.18 & 0.56 & 0.74 \\
\hline Price & -1.11 & 0.52 & 0.03 \\
\hline
\end{tabular}

Table 7 displays the descriptive statistics of the two clusters. Results show that novelty seekers have higher WTB and WTP for the considered product; they are mostly of females who live in the southern part of Italy, aged 35-49, with young children, and a monthly net wage above $€ 1500$.

\section{Discussion}

The results of the statistical analysis performed provide evidence supporting the research hypotheses formulated. As a first comment, based on Kruskal-Wallis and post-hoc tests results, the assumption that FOP claims influence consumer appreciation of the product is confirmed (H1). Results highlight that individuals seeing different claims on the label, perceive product attributes differently with regards to several dimensions. Quite interestingly, consumers exposed to the nutrition-related FOP claim demonstrate an enhanced overall perception of the product as compared to both consumers in the control group and consumers exposed to other claims. Specifically, they show a heightened perception not only of product naturalness and healthiness (as expected), but also an increased appreciation of product innovativeness, environmental friendliness, and taste expectation. These results confirm and extend the findings of various studies concerning the "halo" effect of nutritional and health claims, i.e. their capability to activate a heuristic process that leads the consumer to generalize that the product is preferable for a variety of attributes not explicitly described in the FOP message (Ballco et al., 2019; Benson et al., 2018; Kaur et al., 2017; Menger-Ogle \& Graham, 2018; Talati et al., 2016; Hawley et al., 2013; Andrews et al., 2011). Furthermore, claims referring to hedonic attributes, process innovativeness, and environmental friendliness have a positive effect on product perceptions, in accordance with the conclusions of De Marchi et al. (2016), Gracia et al. (2014).

As far as the relationship between product perception and consumer WTB is concerned (H2), we observed that the perception of healthiness positively influences consumer WTB, as previous research has already pointed out (Huang \& Lu, 2016; Ares, Giménez, \& Gámbaro, 2009; Ares \& Gámbaro, 2007; Ragaert et al., 2004).
Table 7

Segmentation results.

\begin{tabular}{|c|c|c|}
\hline & $\begin{array}{l}\text { Novelty seekers } \\
(31 \%)\end{array}$ & $\begin{array}{l}\text { Conventional } \\
\text { consumers }(69 \%)\end{array}$ \\
\hline \multicolumn{3}{|l|}{ Gender } \\
\hline Male & $41 \%$ & $53 \%$ \\
\hline Female & $59 \%$ & $47 \%$ \\
\hline \multicolumn{3}{|l|}{$\begin{array}{l}\text { Geographical area of residence } \\
\text { in Italy }\end{array}$} \\
\hline Center & $18 \%$ & $21 \%$ \\
\hline NE & $17 \%$ & $20 \%$ \\
\hline NW & $24 \%$ & $27 \%$ \\
\hline South & $41 \%$ & $32 \%$ \\
\hline \multicolumn{3}{|l|}{ Age } \\
\hline $18-34$ & $23 \%$ & $31 \%$ \\
\hline $35-49$ & $47 \%$ & $31 \%$ \\
\hline $50-65$ & $30 \%$ & $38 \%$ \\
\hline \multicolumn{3}{|l|}{ Other demographics } \\
\hline I live alone & $9 \%$ & $18 \%$ \\
\hline $\begin{array}{l}\text { At least one cohabiting minor } \\
\text { child }\end{array}$ & $49 \%$ & $31 \%$ \\
\hline Monthly net wage above $€ 1500$ & $84 \%$ & $76 \%$ \\
\hline Bachelor's degree or higher title & $44 \%$ & $41 \%$ \\
\hline \multicolumn{3}{|l|}{ Consumption habits of olive oil } \\
\hline $\begin{array}{l}\text { Consume olive oil at least a few } \\
\text { times per week }\end{array}$ & $100 \%$ & $98 \%$ \\
\hline $\begin{array}{l}\text { Usually spend } 7 € / L \text { or more for } \\
\text { olive oil }\end{array}$ & $47 \%$ & $39 \%$ \\
\hline \multicolumn{3}{|l|}{ Primary choice criterion } \\
\hline Origin of olives & $24 \%$ & $24 \%$ \\
\hline Brand & $3 \%$ & $2 \%$ \\
\hline Extra virgin olive oil & $48 \%$ & $49 \%$ \\
\hline Price & $6 \%$ & $8 \%$ \\
\hline $\mathrm{PDO} / \mathrm{PGI}$ & $9 \%$ & $8 \%$ \\
\hline Organic certification & $8 \%$ & $6 \%$ \\
\hline Package material & $3 \%$ & $4 \%$ \\
\hline WTB & $61 / 100$ & $37 / 100$ \\
\hline WTP & $2.57 € / 100 \mathrm{ml}$ & $2.24 € / 100 \mathrm{ml}$ \\
\hline
\end{tabular}

In addition, our results show that perceiving the product as familiar, easy to use, natural, tasty and innovative increases consumer WTB. Previous research has investigated the effects of both visual and verbal FOP messages on consumer perception of naturalness and product appreciation. Some contributions focused on the prominent role of visual clues to lead enhanced evaluations of both freshness and appeal (Gvili, 2015). Other contributions documented that textual cues can effectively influence expected naturalness and purchase intention (Machiels \& Karnal, 2016; Rebollar et al., 2017). Our study confirms and extends the latter findings, by suggesting that other dimensions, such as perceived familiarity, ease of use and process innovativeness can influence consumer WTB in the case of a novel food condiment. These results also reinforce those of Verbeke et al. (2009), who disclosed an association between claim, familiarity and product ratings in the functional product category.

Since previous research has shown that product specificity can play a relevant role in moderating the effects of FOP claims and consumption patterns, we included product liking as a predictor of consumer WTB (H3). A statistically significant and positive effect was detected especially for the colour of the condiment and the material of the bottle. These findings are in line with those of Vila-López and Küster-Boluda (2018), Koutsimatis et al. (2012), and Murray and Delahunty (2000). It is also interesting to notice that both the WTB and the WTP for the novel condiment considered in this study are higher 
than those estimated by Roselli et al. (2018) for an extra-virgin olive oil extracted by ultrasound, which is most likely due to its innovative nature.

As a further original contribution to the scientific literature, the research we conducted assessed the influence of individual latent traits on consumer WTB (H4). Evidence was found that the more consumers look for novelty in their shopping, the more they are willing to buy and to pay for Tolly®. Furthermore, choice motives are significantly correlated with WTB and WTP, even if the strength of the correlation is lower than that found with consumer novelty-seeking attitude. In particular, the more sensory appeal is generally important for consumers, the more they are willing to buy the product. This effect also appears in respect to the importance of a healthy and natural content in the choice of food, as already pointed out by Olsen, Menichelli, Sørheim, and Næs (2012) and by Ares and Gámbaro (2007). On the contrary, and in line with our hypothesis, the more price is considered important when choosing food, the less consumers are willing to pay for the product, which is in accordance with the findings of Contini et al. (2015).

Finally, the cluster analysis carried out provided a profile of novelty seekers in Italy and thus of potential target customers for the innovative food product considered. These consumers are mostly adult mothers living in the southern part of Italy, aged 35-49, and having a higher income. These results confirm those obtained by the segmentation study by Cavaliere et al. (2015) which found that females with young children pay particular attention to nutritional claims. Furthermore, based on the segmentation performed, we showed that both the WTP and especially the WTB for Tolly ${ }^{\circledR}$ are higher among "novelty seekers".

The study conducted has some limitations. The first limitation is due to the online setting of the survey which may cause hypothetical bias. This is, however, counterbalanced by the large sample size and the high representativeness of the sample which can be achieved through the online survey method. As a second limitation, the research design did not consider other features of the label design, such as wording and colour of the label, that may have an impact on product perception. Further studies taking into account the possible interactions of these (or other) label features are encouraged, such as Hellier et al.'s study (2012). As a third limitation, the FOP messages proposed were developed by researchers only for the purposes of the study (i.e. to test consumer responses when considering distinct dimensions related to the product) and were not confronted with the strict legal regulation enforced in the EU and national level. Lastly, respondents were asked to assess the novel condiment based only on the visual stimuli of the information provided during the experiment. Future experiments should also take into account the opportunity to carry out a sensory analysis, as widely suggested in the literature (Schouteten, Gellynck, \& Slabbinck, 2019; Lewis, Grebitus, \& Nayga, 2016; Grunert, 2002). Directions for further research that could be worth exploring concern the interactions between FOP messages and other characteristics of the packaging. This topic has been studied in the context of "atypical" food packaging (see e.g. van Ooijen, Fransen, Verlegh, \& Smit, 2016), but to our knowledge, a comprehensive study about how packaging characteristics (i.e. colour, shape, material of the pack, etc.) interact with FOP messages is lacking. Another possible stream of research could focus on the framing of the messages and the possible occurrence of information overload, how messages are framed, and the amount of information that is contained in the message, which all may affect consumption behavior at many levels. Studies exist regarding health claims and sustainability-related claims (Wansink et al., 2004; Mancini, Marchini, \& Simeone, 2017), but further research should take into account other dimensions such as the innovativeness of the process or hedonic messages.

\section{Conclusions}

The research done in this study was designed to assess the effect of different FOP messages on consumer perception, WTB and WTP for a novel food product carrying multiple attributes. The product considered is a new condiment, named Tolly ${ }^{\circledR}$, that has particular nutritional and sensory characteristics obtained through an innovative production process that has a potential positive environmental impact. We also investigated the effect of product liking and consumer individual latent traits (i.e. food choice determinants and novelty seeking) on consumer WTB and then outlined a profile of target consumers.

The results of the survey conducted confirm the initial assumption that FOP message displayed on the label has an effect on how consumer perceive a new product, before its first purchase, while perception of the product, liking of its features, and novelty-seeking orientation affect consumers' WTB. In this respect, we showed that all FOP messages had a statistically significant influence on consumer WTB, but we also pointed out the prominent role of the nutrition-related message that triggers a "halo" effect inducing consumers to enhance overall consumer perception of the product. This suggests that FOP claims, particularly nutritional messages, can be an effective marketing tool for food companies to increase consumer WTB. We also showed that, in regards to the product category considered (i.e. food condiments), much attention must be taken to consumers' perception of specific product features, such as the material of the bottle and the colour of the condiment, as they both were found to have a significant impact on consumer WTB. A further consideration relates to the identification of the most appropriate target for the new condiment. Consumer segmentation carried out based on individual latent traits revealed that "novelty seekers" represent the target group with higher WTB and WTP for the considered product as compared to conventional consumers. Therefore, marketing efforts should be directed to this specific segment.

\section{Funding}

The research was funded within the "Food crossing district" project that was co-financed by the European Regional Development Fund POR FESR 2014-2020 of Emilia-Romagna Region in Italy.

\section{Declaration of Competing Interest}

The authors declare that they have no known competing financial interests or personal relationships that could have appeared to influence the work reported in this paper.

\section{Appendix A. Supplementary material}

Supplementary data to this article can be found online at https://doi. org/10.1016/j.foodres.2019.108962.

\section{References}

Albisu, L. M., Gracia, A., \& Sanjuán, A. I. (2012). Demographics and food consumption: Empirical evidence. The Oxford Handbook of the Economics of Food Consumption and Policy, 1-25. doi:10.1093/oxfordhb/9780199569441.013.0031.

Almeida, B., Valli, E., Bendini, A., \& Gallina Toschi, T. (2017). Semi-industrial ultrasound-assisted virgin olive oil extraction: Impact on quality. European Journal of Lipid Science and Technology, 119(1), 1-7. doi:10.1002/ejlt.201600230.

Andrews, J. C., Burton, S., \& Kees, J. (2011). Is simpler always better? Consumer evaluations of Front-of-Package nutrition symbols. Journal of Public Policy and Marketing, 30(2), 175-190. doi:10.1509/jppm.30.2.175.

Annunziata, A., Mariani, A., \& Vecchio, R. (2019). Effectiveness of sustainability labels in guiding food choices: Analysis of visibility and understanding among young adults. Sustainable Production and Consumption, 17, 108-115. doi:10.1016/j.spc.2018.09.005.

Ares, G., \& Gámbaro, A. (2007). Influence of gender, age and motives underlying food choice on perceived healthiness and willingness to try functional foods. Appetite, 49(1), 148-158. doi:10.1016/J.APPET.2007.01.006.

Ares, G., Giménez, A., \& Gámbaro, A. (2009). Consumer perceived healthiness and willingness to try functional milk desserts. Influence of ingredient, ingredient name and 
health claim. Food Quality and Preference, 20(1), 50-56. doi:10.1016/ j.foodqual.2008.07.002.

Ballco, P., De-Magistris, T., \& Caputo, V. (2019). Consumer preferences for nutritional claims: An exploration of attention and choice based on an eye-tracking choice experiment. Food Research International, 116, 37-48. doi:10.1016/j.foodres.2018.12.031.

Benson, T., Lavelle, F., Bucher, T., McCloat, A., Mooney, E., \& Egan, B., et al. (2018). The impact of nutrition and health claims on consumer perceptions and portion size selection: Results from a nationally representative survey. Nutrients. doi:10.3390/ nu10050656.

Bernard, J. C., Duke, J. M., \& Albrecht, S. E. (2019). Do labels that convey minimal, redundant, or no information affect consumer perceptions and willingness to pay? Food Quality and Preference, 71, 149-157. doi:10.1016/j.foodqual.2018.06.012.

Bialkova, S., Sasse, L., \& Fenko, A. (2016). The role of nutrition labels and advertising claims in altering consumers' evaluation and choice. Appetite, 96, 38-46. doi:10.1016/ j.appet.2015.08.030

Biondi, B., Van der Lans, I. A., Mazzocchi, M., Fischer, A. R. H., Van Trijp, H. C. M., \& Camanzi, L. (2019). Modelling consumer choice through the random regret minimization model: An application in the food domain. Food Quality and Preference, 73, 97-109. doi:10.1016/j.foodqual.2018.12.008.

Bradley, M. M., \& Lang, P. J. (1994). Measuring emotion: The self-assessment manikin and the semantic differential. Journal of Behavior Therapy and Experimental Psychiatry, 25(1), 49-59. doi:10.1016/0005-7916(94)90063-9.

Cagalj, M., Haas, R., \& Morawetz, U. B. (2016). Effects of quality claims on willingness to pay for organic food. British Food Journal, 118(9), 2218-2233. doi:10.1108/ BFJ-11-2015-0453.

Caracciolo, F., Vecchio, R., Lerro, M., Migliore, G., Schifani, G., \& Cembalo, L. (2019). Natural versus enriched food: Evidence from a laboratory experiment with chewing gum. Food Research International, 122, 87-95. doi:10.1016/j.foodres.2019.03.069.

Carrillo, E., Varela, P., \& Fiszman, S. (2012). Effects of food package information and sensory characteristics on the perception of healthiness and the acceptability of enriched biscuits. Food Research International, 48(1), 209-216. doi:10.1016/ j.foodres.2012.03.016.

Cavaliere, A., Ricci, E. C., \& Banterle, A. (2015). Nutrition and health claims: Who is interested? An empirical analysis of consumer preferences in Italy. Food Quality and Preference, 41, 44-51. doi:10.1016/j.foodqual.2014.11.002

Cavallo, C., \& Piqueras-Fiszman, B. (2017). Visual elements of packaging shaping healthiness evaluations of consumers: The case of olive oil. Journal of Sensory Studies, 32(1), e12246. doi:10.1111/joss.12246.

Cecchini, L., Torquati, B., \& Chiorri, M. (2018). Sustainable agri-food products: A review of consumer preference studies through experimental economics. Agricultural Economics (Czech Republic), 64(12), 554-565. doi:10.17221/272/2017-AGRICECON.

Chernev, A., Böckenholt, U., \& Goodman, J. (2015). Choice overload: A conceptual review and meta-analysis. Journal of Consumer Psychology, 25(2), 333-358. doi:10.1016/ j.jcps.2014.08.002.

Contini, C., Casini, L., Stefan, V., Romano, C., Juhl, H. J., \& Lähteenmäki, L., et al. (2015). Some like it healthy: Can socio-demographic characteristics serve as predictors for a healthy food choice? Food Quality and Preference, 46, 103-112. doi:10.1016/ j.foodqual.2015.07.009.

D’Souza, C., Taghian, M., Lamb, P., \& Peretiatko, R. (2007). Green decisions: Demographics and consumer understanding of environmental labels. International Journal of Consumer Studies, 31(4), 371-376. doi:10.1111/j.1470-6431.2006.00567.x.

Darian, J. C., \& Tucci, L. (2011). Perceived health benefits and food purchasing decisions. Journal of Consumer Marketing, 28(6), 421-428. doi:10.1108/07363761111165930.

De Marchi, E., Caputo, V., Nayga, R. M., \& Banterle, A. (2016). Time preferences and food choices: Evidence from a choice experiment. Food Policy. doi:10.1016/ j.foodpol.2016.05.004

Ducrot, P., Julia, C., Méjean, C., Kesse-Guyot, E., Touvier, M., \& Fezeu, L. K., et al. (2016). Impact of different front-of-pack nutrition labels on consumer purchasing intentions: A randomized controlled trial. American Journal of Preventive Medicine, 50(5), 627-636. doi:10.1016/J.AMEPRE.2015.10.020.

Commission, E. (2015). Circular economy package: Questions \& answers. Fact Sheet.

European Commission. (2016). Commission Staff Working Paper: Guidance on the Implementation/Application of Directive 2005/29/EC on Unfair Commercial Practices, SWD (2016) 163 final.

Federal Trade Comission. (2012). Part VII, 16 CFR Part 260: Guides for the Use of Environmental Marketing Claims; Final Rule. Federal Register. Retrieved from https: //www.ftc.gov/sites/default/files/documents/federal_register_notices/guides-useenvironmental-marketing-claims-green-guides/greenguidesfrn.pdf

Galati, A., Tulone, A., Moavero, P., \& Crescimanno, M. (2019). Consumer interest in information regarding novel food technologies in Italy: The case of irradiated foods. Food Research International, 119, 291-296. doi:10.1016/j.foodres.2019.01.065.

Gorski Findling, M. T., Werth, P. M., Musicus, A. A., Bragg, M. A., Graham, D. J., \& Elbel, B., et al. (2018). Comparing five front-of-pack nutrition labels' influence on consumers' perceptions and purchase intentions. Preventive Medicine, 106, 114-121. doi:10.1016/j.ypmed.2017.10.022.

Gracia, A., Barreiro-Hurlé, J., \& Galán, B. L. (2014). Are local and organic claims complements or substitutes? A consumer preferences study for eggs. Journal of Agricultural Economics, 65(1), 49-67. doi:10.1111/1477-9552.12036.

Grunert, K. G. (2002). Current issues in the understanding of consumer food choice. Trends in Food Science \& Technology, 13(8), 275-285. doi:10.1016/S0924-2244(02)00137-1.

Grunert, K. G. (2019). International segmentation in the food domain: Issues and approaches. Food Research International, 115, 311-318. doi:10.1016/ j.foodres.2018.11.050.
Gvili, Y., et al. (2015). Fresh from the tree: Implied motion improves food evaluation. Food Quality and Preference, 46, 160-165. doi:10.1016/j.foodqual.2015.07.015.

Hawley, K. L., Roberto, C. A., Bragg, M. A., Liu, P. J., Schwartz, M. B., \& Brownell, K. D. (2013). The science on front-of-package food labels. Public Health Nutrition, 16(3), 430-439. doi:10.1017/S1368980012000754.

Hellier, E., Tucker, M., Newbold, L., Edworthy, J., Griffin, J., \& Coulson, N. (2012). The ef fects of label design characteristics on perceptions of genetically modified food. Journal of Risk Research, 15(5), 533-545. doi:10.1080/13669877.2011.646288.

Huang, L., \& Lu, J. (2016). The impact of package color and the nutrition content labels on the perception of food healthiness and purchase intention. Journal of Food Products Marketing, 22(2), 191-218. doi:10.1080/10454446.2014.1000434.

International Organization for Standardization (2008). ISO 14021:1999: Environmental labels and declarations - self-declared environmental claims (Type I environmental labelling - principles and procedures and Type II environmental labelling), Geneva, available at: www.iso.org/obp/ui/\#iso:std:iso:14021:ed-1:v1:en.

Kaulmann, A., \& Bohn, T. (2014). Carotenoids, inflammation, and oxidative stress-implications of cellular signaling pathways and relation to chronic disease prevention. Nutrition Research, 34(11), 907-929. doi:10.1016/j.nutres.2014.07.010.

Kaur, A., Scarborough, P., \& Rayner, M. (2017). A systematic review, and meta-analyses, of the impact of health-related claims on dietary choices. International Journal of Behavioral Nutrition and Physical Activity, 14(1), 1-17. doi:10.1186/s12966-017-0548-1.

Krystallis, A., Grunert, K. G., de Barcellos, M. D., Perrea, T., \& Verbeke, W. (2012). Consumer attitudes towards sustainability aspects of food production: Insights from three continents. Journal of Marketing Management, 28(3-4), 334-372. doi:10.1080/ 0267257X.2012.658836.

Küster, I., Vila, N., \& Sarabia, F. (2019). Food packaging cues as vehicles of healthy in formation: Visions of millennials (early adults and adolescents). Food Research International, 119(November 2018), 170-176. doi:10.1016/j.foodres.2019.01.051.

Kuvykaite, R., Dovaliene, A., \& Navickiene, L. (2009). Impact of package elements on consumer's purchase decision. Economics and Management, 14, 441-447. doi:10.5755/ j01.em.0.14.9405.

Lewis, K. E., Grebitus, C., \& Nayga, R. M. (2016). The importance of taste in experimental auctions: Consumer" valuation of calorie and sweetener labeling of soft drinks. Agricultural Economics, 47(1), 47-57. doi:10.1111/agec.12208.

Machiels, C. J. A., \& Karnal, N. (2016). See how tasty it is? Effects of symbolic cues on product evaluation and taste. Food Quality and Preference, 52, 195-202. doi:10.1016/ j.foodqual.2016.04.014

Magnier, L., Schoormans, J., \& Mugge, R. (2016). Judging a product by its cover: Packaging sustainability and perceptions of quality in food products. Food Quality and Preference, 53, 132-142. doi:10.1016/j.foodqual.2016.06.006.

Mancini, P., Marchini, A., \& Simeone, M. (2017). Which are the sustainable attributes affecting the real consumption behaviour? Consumer understanding and choices. British Food Journal, 119(8), 1839-1853. doi:10.1108/BFJ-11-2016-0574.

Manning, K. C., Bearden, W. O., \& Madden, T. J. (1995). Consumer innovativeness and the adoption process. Journal of Consumer Psychology, 4(4), 329-345. doi:10.1207/ s15327663jcp0404_02.

McDaniel, C., \& Baker, R. C. (1977). Convenience food packaging and the perception of product quality. Journal of Marketing, 41(4), 57-58. doi:10.2307/1250234.

Menger-Ogle, A. D., \& Graham, D. J. (2018). The influence of front-of-package nutrition claims on food perceptions and purchase intentions among Nepali consumers. Food Quality and Preference, 66, 160-170. doi:10.1016/j.foodqual.2017.12.017.

Miller, K. M., Hofstetter, R., Krohmer, H., \& Zhang, Z. J. (2011). How should consumers Willingness to pay be measured? An empirical comparison of state-of-the-art ap proaches. Journal of Marketing Research, 48(1), 172-184. doi:10.1509/jmkr.48.1.172.

Mueller Loose, S., \& Szolnoki, G. (2012). Market price differentials for food packaging characteristics. Food Quality and Preference, 25(2), 171-182. doi:10.1016/ j.foodqual.2012.02.009.

Murray, J. M., \& Delahunty, C. M. (2000). Mapping consumer preference for the sensory and packaging attributes of Cheddar cheese. Food Quality and Preference, 11(5), 419-435. doi:10.1016/s0950-3293(00)00017-3.

Nancarrow, C., Tiu Wright, L., \& Brace, I. (1998). Gaining competitive advantage from packaging and labelling in marketing communications. British Food Journal, 100(2), 110-118. doi:10.1108/00070709810204101.

Nayga, R. M. (1997). Impact of sociodemographic factors on perceived importance of nutrition in food shopping. Journal of Consumer Affairs, 31(1), 1-9. doi:10.1111/ j.1745-6606.1997.tb00823.x.

Newman, C. L., Burton, S., Andrews, J. C., Netemeyer, R. G., \& Kees, J. (2018). Marketers' use of alternative front-of-package nutrition symbols: An examination of effects on product evaluations. Journal of the Academy of Marketing Science, 46(3), 453-476. doi:10.1007/s11747-017-0568-z

Oliveira, D., Ares, G., \& Deliza, R. (2018). The effect of health/hedonic claims on consumer hedonic and sensory perception of sugar reduction: Case study with orange/passionfruit nectars. Food Research International, 108(February), 111-118. doi:10.1016/ j.foodres.2018.03.003.

Olsen, N. V., Menichelli, E., Sørheim, O., \& Næs, T. (2012). Likelihood of buying healthy convenience food: An at-home testing procedure for ready-to-heat meals. Food Quality and Preference, 24(1), 171-178. doi:10.1016/J.FOODQUAL.2011.11.001

Panzone, L., Hilton, D., Sale, L., \& Cohen, D. (2016). Socio-demographics, implicit attitudes, explicit attitudes, and sustainable consumption in supermarket shopping. Journal of Economic Psychology, 55, 77-95. doi:10.1016/J.JOEP.2016.02.004.

Priven, M., Baum, J., Vieira, E., Fung, T., \& Herbold, N. (2015). The influence of a factitious free-from food product label on consumer perceptions of healthfulness. Journal of the Academy of Nutrition and Dietetics, 115(11), 1808-1814. doi:10.1016/ j.jand.2015.03.013. 
Ragaert, P., Verbeke, W., Devlieghere, F., \& Debevere, J. (2004). Consumer perception and choice of minimally processed vegetables and packaged fruits. Food Quality and Preference, 15(3), 259-270. doi:10.1016/S0950-3293(03)00066-1.

Rebollar, R., et al. (2017). How material, visual and verbal cues on packaging influence consumer expectations and willingness to buy: The case of crisps (potato chips) in Spain'. Food Research International, 99, 239-246. doi:10.1016/j.foodres.2017.05.024.

Rettie, R., \& Brewer, C. (2000). The verbal and visual components of package design. Journal of Product \& Brand Management, 9(1), 56-70. doi:10.1108/10610420010316339.

Roberto, C. A., \& Khandpur, N. (2014). Improving the design of nutrition labels to promote healthier food choices and reasonable portion sizes. International Journal of Obesity, 38(suppl. 1), S25-S33. doi:10.1038/ijo.2014.86.

Roberto, C. A., Bragg, M. A., Seamans, M. J., Mechulan, R. L., Novak, N., \& Brownell, K. D. (2012). Evaluation of consumer understanding of different front-of-package nutrition labels, 2010-2011. Preventing Chronic Disease, 9(9), 2010-2011. doi:10.5888/ pcd9.120015.

Roberto, C. A., Shivaram, M., Martinez, O., Boles, C., Harris, J. L., \& Brownell, K. D. (2012). The Smart Choices front-of-package nutrition label. Influence on perceptions and intake of cereal. Appetite, 58(2), 651-657. doi:10.1016/j.appet.2012.01.003.

Roselli, L., Cicia, G., Cavallo, C., Del Giudice, T., Carlucci, D., \& Clodoveo, M. L., et al. (2018). Consumers' willingness to buy innovative traditional food products: The case of extra-virgin olive oil extracted by ultrasound. Food Research International, 108, 482-490. doi:10.1016/j.foodres.2018.03.070.

Scalbi, S., Bendini, A., Biondi B., Camanzi, L., Cascone, C., Chiavetta, C., Sposato, P., Tesini, F., Valli, E., Gallina Toschi, T. (2019). TOLLY®: l'olio rosso di oliva e pomodoro, ottenuto applicando l'economia circolare. In Arcese, G., Cellura, M., Cortesi, S., Cutaia, L., Lucchetti, M. C., Mancuso, E., Mistretta, M., Montauti, C., Scalbi, S. (Eds.) Atti del XIII Convegno della Rete Italiana LC - Il Life Cycle Thinking a supporto delle strategie di mitigazione e adattamento ai cambiamenti climatici (pp. 358-366) ENEA, Rome. ISBN: 978-88-8286-389-0. Available at https://www.enea.it/ en/publications/abstract/lyfe-cycle-thinking-2019.

Schouteten, J. J., Gellynck, X, \& Slabbinck, H. (2019). Influence of organic labels on consumer's flavor perception and emotional profiling: Comparison between a central location test and home-use-test. Food Research International, 116(June 2018), 1000-1009. doi:10.1016/j.foodres.2018.09.038.

Shepherd, R., Sparks, P., Bellier, S., \& Raats, M. M. (1991). The effects of information on sensory ratings and preferences: The importance of attitudes. Food Quality and Preference, 3(3), 147-155. doi:10.1016/0950-3293(91)90051-F.

Silayoi, P., \& Speece, M. (2004). Packaging and purchase decisions: An exploratory study on the impact of involvement level and time pressure. British Food Journal, 106(8), 607-628. doi:10.1108/00070700410553602.

Stanton, J. V., \& Cook, L. A. (2019). Product knowledge and information processing of organic foods. Journal of Consumer Marketing, 36(1), 240-252. doi:10.1108/ JCM-07-2017-2275.

Steptoe, A., Pollard, T. M., \& Wardle, J. (1995). Development of a Measure of the Motives Underlying the Selection of Food: The Food Choice Questionnaire. Appetite, 25(3), 267-284. doi:10.1006/appe.1995.0061.
Talati, Z., Pettigrew, S., Hughes, C., Dixon, H., Kelly, B., \& Ball, K., et al. (2016). The combined effect of front-of-pack nutrition labels and health claims on consumers' evaluation of food products. Food Quality and Preference, 53, 57-65. doi:10.1016/ j.foodqual.2016.05.016.

Tórtora, G., Machín, L., \& Ares, G. (2019). Influence of nutritional warnings and other label features on consumers' choice: Results from an eye-tracking study. Food Research International, 119, 605-611. doi:10.1016/j.foodres.2018.10.038.

USDA (2014). Food labeling and label approval, available at: https://www.fsis.usda.gov/ wps/portal/fsis/topics/regulatory-compliance/labeling, accessed 30th October, 2019.

Van Der Zanden, L. D. T., Van Kleef, E., De Wijk, R. A., \& Van Trijp, H. C. M. (2014). Understanding heterogeneity among elderly consumers: An evaluation of segmentation approaches in the functional food market. Nutrition Research Reviews, 27(1), 159-171. doi:10.1017/S0954422414000092.

van Kleef, E., van Trijp, H. C. M., \& Luning, P. (2005). Functional foods: Health claim-food product compatibility and the impact of health claim framing on consumer evaluation. Appetite, 44(3), 299-308. doi:10.1016/j.appet.2005.01.009.

Van Loo, E. J., Caputo, V., Nayga, R. M., Seo, H.-S., Zhang, B., \& Verbeke, W. (2015). Sustainability labels on coffee: Consumer preferences, willingness-to-pay and visual attention to attributes. Ecological Economics, 118, 215-225. doi:10.1016/ J.ECOLECON.2015.07.011.

van Ooijen, I., Fransen, M. L., Verlegh, P. W. J., \& Smit, E. G. (2016). Atypical food packaging affects the persuasive impact of product claims. Food Quality and Preference, 48, 33-40. doi:10.1016/J.FOODQUAL.2015.08.002.

van Trijp, H. C. M., \& van der Lans, I. A. (2007). Consumer perceptions of nutrition and health claims. Appetite, 48(3), 305-324. doi:10.1016/J.APPET.2006.09.011.

Van Wezemael, L., Caputo, V., Nayga, R. M., Chryssochoidis, G., \& Verbeke, W. (2014). European consumer preferences for beef with nutrition and health claims: A multi-country investigation using discrete choice experiments. Food Policy, 44, 167-176. doi:10.1016/j.foodpol.2013.11.006.

Vanhonacker, F., Kühne, B., Gellynck, X., Guerrero, L., Hersleth, M., \& Verbeke, W. (2013). Innovations in traditional foods: Impact on perceived traditional character and consumer acceptance. Food Research International, 54(2), 1828-1835. doi:10.1016/ j.foodres.2013.10.027.

Varela, P., Ares, G., Giménez, A., \& Gámbaro, A. (2010). Influence of brand information on consumers' expectations and liking of powdered drinks in central location tests. Food Quality and Preference, 21(7), 873-880. doi:10.1016/j.foodqual.2010.05.012.

Verain, M. C. D., Bartels, J., Dagevos, H., Sijtsema, S. J., Onwezen, M. C., \& Antonides, G. (2012). Segments of sustainable food consumers: A literature review. International Journal of Consumer Studies, 36(2), 123-132. doi:10.1111/j.1470-6431.2011.01082.x.

Verbeke, W., Scholderer, J., \& Lähteenmäki, L. (2009). Consumer appeal of nutrition and health claims in three existing product concepts. Appetite, 52(3), 684-692. doi:10.1016/j.appet.2009.03.007.

Vila-López, N., \& Küster-Boluda, I. (2018). Commercial versus technical cues to position a new product: Do hedonic and functional/healthy packages differ? Social Science and Medicine, 198, 85-94. doi:10.1016/j.socscimed.2017.12.018.

Wansink, B., Sonka, S. T., \& Hasler, C. M. (2004). Front-label health claims: When less is more. Food Policy, 29(6), 659-667. doi:10.1016/j.foodpol.2004.10.004. 